\title{
Comparison of IQ, EI, Sports Performance, and Psychological Characteristics of Young Male Soccer Players in Different Playing Positions
}

\author{
${ }^{1}$ Nima Nakisa, ${ }^{2}$ Mahboobeh Ghasemzadeh Rahbardar ${ }^{*}$ \\ ${ }^{1}$ Faculty of Physical Education and Sport Sciences, Kish International Campus, University of Tehran, Kish \\ Island, Iran. ${ }^{2}$ Mashhad University of Medical Sciences, Mashhad, Iran.
}

Submitted 25 July 2020; Accepted in final form 22 September 2020.

\begin{abstract}
Background. Soccer is a popular sport with a large number of players all over the world. Besides, it has considerable economic and social effects. Thus, it is necessary to find out the factors which influence soccer players' performance. Objectives. The purpose of this investigation was to determine whether there is a significant correlation between intellectual intelligence (I.Q) (Raven's progressive matrices) and emotional intelligence (EI) (Bar-On emotional intelligence scale) with the performance (Charbonneau sports performance questionnaire), and assess the psychological characteristics of young male soccer players in different playing positions and the descriptive method with a correlation technique was used. Methods. Pearson correlation coefficient was used for questions analysis and One-way ANOVA was used for testing the hypothesizes. 120 young Iranian male soccer players aged 17-19 from different soccer schools participated in the study. The players were divided into four playing positions: forwards, midfielders, defenders, and goalkeepers. Results. The obtained data revealed a positive linear correlation between soccer players' IQ, EQ, and sports performance. Also, significant differences were observed between Bar-On subscale scores of the players in different playing positions. Conclusion. The obtained outcomes reinforce the hypothesis that positional differences in terms of psychological characteristics exist. In addition, it might be concluded that young soccer players might be differentiated by their psychological skills and their playing positions.
\end{abstract}

KEYWORDS: Soccer, Soccer Players, Intelligence Quotient, Emotional Intelligence, Performance, Psychological Characteristics, Playing Positions.

\section{INTRODUCTION}

Soccer as an intensive alternate team sport requires physical, tactical, and technical skills (1), along with psychological talents $(2,3)$ for the best possible performance. In other words, performance is defined by a physical, tactical, and technical practice, required to achieve the elite level in soccer (4).

Several skills are necessary to employ learned strategies and tactics during competitions or training and players are not always successful in controlling their potential (5). Furthermore, these skills might be controlled by different parameters including "intelligence quotient" (I.Q), "emotional intelligence" (EI), and "playing position" $(6,7)$. Thus, strengthening the psychological parameters and practicing psychological skills is really essential for the sports competition.

Van Jaarsveld described that IQ is related to an individual's analytical, logical, intellectual, and rational abilities. It is also an indication of one's

*. Corresponding Author:

Mahboobeh Ghasemzadeh Rahbardar, Ph.D.

E-mail: ghasemzadeh_mahboobeh@yahoo.com 
ability to focus on tasks, learn new things, and recall and retain objective information. Additionally, it reveals how an individual manipulates numbers, reasons, solves problems by using prior knowledge, etc (8). IQ or intelligence is a significant element that often defines victory in sports, mainly in particular branches including soccer, volleyball, basketball, tennis, etc that require to think accurately and quickly and to act rapidly to anticipate the opponent. Consequently, intelligence achievement in sports is very essential $(9,10)$.

Alternatively, EI is related to non-cognitive capacities of intelligence and indicates the ability to read the social and political circumstances, to comprehend instinctively what others need or want, and what their strong and weak points are. It is an ability to stay steady and balanced by stress, respond logically to life experiences and crises, use emotions to solve problems, and consequently provide a more effective life (6). In this regard, Gagné introduced his theoretical model of "Differentiated Model of Gift and Talent" and listed four areas of natural abilities including; 1 . Intellectual abilities (memory, reasoning, judgment, etc), 2. Creative abilities (imagination, originality, inventiveness, etc), 3. Socioaffective abilities (influence, communication, empathy, perceptiveness), 4. Sensorimotor abilities (strength, sensitivity, endurance, coordination, etc) (11). In addition, it was reported that psychological disposition is one of the main elements in sports performance because of the effect that it would have on players' competitive success $(12,13)$. Likewise, some investigations indicated that physiological factors represent $45-48 \%$ of performance in sports, but if the psychological parameters are added, the proportion increases around $79-85 \%$ in particular sports such as rugby, soccer, wrestling, and basketball (14-16). In addition, as stated by Kauss, "how you feel is how you will play" (17). The powerful relation between athletic performance and emotions has attracted researches to find techniques to regulate and control emotions. Numerous studies have shown a considerable correlation between EI and other factors including athletic performance (18), selfefficacy (19), and physical and mental health (20). It was reported that EI is crucial in team sports and individual sports and could be a fundamental issue in an athlete's performance and team setting. In other terms, EI is an important factor in determining if an athlete wins or not and it can make or break a team (6).
On the other hand, each playing position has particular psychological requirements. This subject will be an important field of research, as demands placed upon players vary according to the playing position. There is evidence that players in different playing positions tend to have different psychological skill levels $(7,21)$. Therefore, evaluating personality traits is a reliable approach for studying the effect of the psychological factors on sports performance.

Hence, the main purposes of the current investigation were: 1 . to assess the relation between IQ (Raven's progressive matrices), EI (Bar-On emotional intelligence scale), and performance (Charbonneau sports performance questionnaire), and 2. to determine the differences between psychological profile (Bar-On emotional intelligence scale) of youth soccer players in different playing positions. It was hypothesized that this investigation could provide beneficial awareness into recognizing of some psychological features that might influence sports performance and also psychological characteristics of each playing position to improve psychological skills training programs in soccer. Furthermore, it may show the significance of the usage of psychological skills in succeeding in youth soccer competitions.

\section{MATERIALS AND METHODS}

Trial Design. This study was a descriptive correlational and causal-comparative type (postevent).

Participants. This study was conducted on Iranian youth soccer players $(\mathrm{n}=120)$ from different soccer schools (17-19 years old). Soccer players were classified into four positional groups based on their primary playing positions at the school team; forwarders $(n=30)$, midfielders $(n$ $=30)$, defenders $(n=30)$, and goalkeepers $(n=$ 30). The sample size of the present study was calculated based on previous studies (7).

Selection Criteria. The inclusion criteria of the present study were being a member of the school soccer team at least for one year, age range between 17 and 19 years, and absence of debilitating and acute physical or mental diseases. Players with a specific physical or psychiatric disorder were excluded from the study through medical and psychiatric interviews by a physician and a clinical psychologist.

Measuring Instruments. The study variables involved IQ, EI, sports performance, and psychological characteristics of young male soccer 
players in different playing positions. The research tools included: Raven's progressive matrices, BarOn emotional intelligence scale, and Charbonneau sports performance questionnaire.

Raven's Standard Progressive Matrices. The Raven's intelligence test is a 60 -item test known as Raven's progressive matrices. The Raven's intelligence test is one of the non-verbal intelligence tests developed by the Englishman John C. Raven. Later in the analysis of factor analysis, it was found that it is a good criterion for evaluating the general IQ or Spearman's "g". This test was first designed in 1938. In the following years, different versions of it were presented, the last version of which was designed in 2018 as Raven's 2 intelligence test. Raven intelligence test is designed from a set of images that have a general structural image pattern. An image has been deleted in this template. One has to guess which image can replace the vacancy according to the pattern of images that exist $(22,23)$.

An earlier investigation calculated the correlation coefficient between the scores of 60 subjects in the Wechsler adult intelligence scale (verbal section) and their scores in Raven's progressive matrices. The value of the correlation coefficient was 0.73 , which was significant at the level of 0.01 . Therefore, considering the significance of the obtained coefficient, it can be concluded that Raven's progressive matrices have an acceptable validity to measure the level of students' intelligence and achieve their IQ (Paper is in Persian).

Bar-on Emotional Intelligence Scale. In the current study, the Bar-On emotional intelligence scale is used to assess the emotional intelligence and psychological profile of different playing positions. This scale was designed in 1997 by Bar-On based on 5 degrees Likert scale from "completely agree" to "completely disagree". It consists of 90 questions and some of the questions are scoring positively and some are scoring negatively. Bar-On presents the notion of emotional intelligence in 5 parts including A. Intrapersonal intelligence, B. Interpersonal intelligence, C. Adaptability, D. Stress management, E. General mood. It also contains 15 subscales namely, 1. Problem-Solving, 2. Happiness, 3. Independence, 4. Stress Tolerance, 5. Self-Actualization, 6. Emotional SelfAwareness, 7. Reality Testing, 8. Interpersonal relationship, 9. Optimism, 10. Self-Regard, 11. Impulse Control, 12. Flexibility, 13. Social
Responsibility, 14. Empathy, and 15. Assertiveness (24).

The validity and reliability of this inquiry form have been evaluated by several methods. The mean Cranach's alpha coefficient in valuing internal consistency for all scales are high (it is from low Coefficient 0.69) for social responsibility to high coefficient 0.86 ) for the subscale of self-regard. Bar-On in his studies, with attention to the answers of participants and with attention to the idea of experts concluded that this questionnaire has a high face and content validity (25). The reliability coefficient of this questionnaire with the time interval of 4 months is calculated 0.73, in Iran (26). In another study, the reliability coefficient of this test is acquired 0.74, by Cranach's alpha (27).

Charbonneau Sports Performance Questionnaire. This sports performance questionnaire was designed in 2001 by Charbonneau (28). It was prepared using a fivepoint Likert scale and was created to estimate the athletes' performance. These questions are designed on a scale of 1 (very poor) to 5 (excellent). The score range was from 5-25. High scores and low scores show high performance and low performance, respectively. The mean reliability coefficients of this questionnaire were calculated and reported as 0.71 by Charbonneau. The questionnaire was translated to Persian and its formal validity was checked by six specialists in sport psychology. In addition, to control the reliability of the questionnaire, it was tested on 50 students of Iran University of Medical Sciences and the mean Cronbach alpha coefficient was 0.91 (29). This questionnaire was used to evaluate the soccer players' exercise performance.

Statistical Analysis Methods. In this research, data were analyzed by version 25 of SPSS and frequency table and frequency percent was regulated by the descriptive statistical method and with attention to the method and nature of research, Pearson correlation coefficient was used for questions analysis and One-way ANOVA was used for testing the hypothesizes.

\section{RESULTS}

Reliability and Normality of the Employed Questionnaires. At first, using the scores of 60 subjects the reliability of the Charbonneau sports performance questionnaire, Raven's standard progressive matrices, and Bar-On emotional intelligence scale were estimated by measuring Cronbach's alpha. The Cronbach's alpha was 
0.882 for the Charbonneau sports performance questionnaire, 0.798 for questions 1-24 (6-choice questions), and 0.753 for questions 25-60 (8choice questions) of Raven's standard progressive matrices, and 0.841 for Bar-On emotional intelligence scale and (Table 1).

Then, Kolmogrov-Smirnov and Shapiro-Wilk were used to check the normality of the obtained data. The results are shown in Table 2.

The null hypothesis is that the data has a normal distribution and the $\mathrm{H}_{1}$ hypothesis says that the data does not have a normal distribution. Since the numbers in the sig. part are greater than 0.05 , they are not statistically significant, and therefore the null hypothesis is accepted, meaning that the data have a normal distribution. Also, since our data has a normal distribution, parametric tests such as Pearson correlation and One-way ANOVA tests can be used.

Correlation Between Sports Performance,

IQ, and EI. Pearson correlation test was used to test the relationship between IQ and sports performance. There was a significant correlation between IQ and sports performance $(\mathrm{p}=0.047, \mathrm{n}=$ 120 , and $\mathrm{r}=0.581$ ). Also, a significant positive correlation was observed between EI and sports performance $(\mathrm{p}=0.000, \mathrm{n}=120$, and $\mathrm{r}=0.821)$.

Thus, it can be concluded that $33 \%$ (r2) of sports performance rates might be predicted by players' EI scores and $67 \%\left(r^{2}\right)$ of sports performance rates might be predicted by players' EI scores (Table 3).

Comparing the IQ and EI of Soccer Players in Different Playing Positions. Comparing the obtained IQ scores of soccer players in different playing positions displayed that there is no significant difference among them. But, the data of EI revealed that the EI scores of midfielders are higher than defenders $(\mathrm{p}<0.05)$ and the EI scores of forwards are higher than defenders and goalkeepers $(\mathrm{p}<0.01)$.

Table 1. The Estimated Cronbach's Alpha for the Charbonneau Sports Performance Questionnaire, Raven's Standard Progressive Matrices, and Bar-On Emotional Intelligence Scale Using the Scores of 60 Subjects

\begin{tabular}{lcc}
\hline Tests & \multicolumn{2}{c}{ Reliability Statistics } \\
\cline { 2 - 3 } & Cronbach's Alpha & N of Items \\
\hline $\begin{array}{l}\text { Charbonneau sports performance questionnaire } \\
\text { Raven's standard progressive matrices (questions 1-24, 6-choice } \\
\text { questions) }\end{array}$ & 0.882 & 5 \\
$\begin{array}{l}\text { Raven's standard progressive matrices (questions 25-60, 8-choice } \\
\text { questions) }\end{array}$ & 0.798 & 24 \\
Bar-On emotional intelligence scale & 0.753 & 36 \\
\hline
\end{tabular}

Table 2. Kolomogrov-Smirnov and Shapiro-Wilk Tests Results

\begin{tabular}{lcccc}
\hline & \multicolumn{2}{c}{ Kolmogorov-Smirnov } & \multicolumn{2}{c}{ Shapiro-Wilk } \\
\hline & Statistic & $\mathbf{p}$ & Statistic & p \\
\hline Sports performance & 0.102 & $0.200^{*}$ & 0.960 & 0.352 \\
IQ & 0.108 & $0.200^{*}$ & 0.957 & 0.299 \\
EI & 0.121 & $0.200^{*}$ & 0.965 & 0.474 \\
\hline
\end{tabular}

IQ: Intelligence Quotient; EI: Emotional Intelligence; "Lower Bound of the True Significance

Table 3. Pearson Correlation Tests Results

\begin{tabular}{ccc}
\hline & Sports Performance & IQ \\
\hline Sports Performance and IQ & & $0.581^{*}$ \\
Pearson correlation & 1 & 0.047 \\
Sig. (2-tailed) & 120 & 120 \\
N & Sports Performance & EQ \\
Sports Performance and EQ & 1 & $0.821^{* *}$ \\
Pearson correlation & 120 & 0.000 \\
Sig. (2-tailed) & 120 \\
\hline N & & 120 \\
\hline
\end{tabular}

IQ: Intelligence Quotient; EI: Emotional Intelligence. ${ }^{*}$ Correlation is significant at the 0.05 level (2-tailed), ${ }^{* * *}$ Correlation is significant at the 0.01 level (2-tailed). 
Table 4. Comparing the IQ and EQ Scores of Soccer Players in Different Playing Positions

\begin{tabular}{lcccccc}
\hline & $\begin{array}{c}\text { Goalkeepers }(\mathbf{n}=\mathbf{3 0}) \\
\text { Mean } \pm \text { SD }\end{array}$ & $\begin{array}{c}\text { Defenders }(\mathbf{n}=\mathbf{3 0}) \\
\text { Mean } \pm \text { SD }\end{array}$ & $\begin{array}{c}\text { Midfielders }(\mathbf{n}=\mathbf{3 0}) \\
\text { Mean } \pm \text { SD }\end{array}$ & $\begin{array}{c}\text { Forwards }(\mathbf{n}=\mathbf{3 0}) \\
\text { Mean } \pm \text { SD }\end{array}$ & $\begin{array}{c}\text { F }(\mathbf{3}, \\
\mathbf{1 1 6})\end{array}$ & $\mathbf{p}$ \\
\hline IQ & $107.33 \pm 18.44$ & $116.4 \pm 9$ & $111.28 \pm 13.67$ & $115.6 \pm 11.05$ & 0.3276 & 0.8054 \\
EI & $319.66 \pm 6.64$ & $314.25 \pm 22.47$ & $344.5 \pm 12.38^{*}$ & $367.75 \pm 15.51^{\text {\#*** }}$ & 8.739 & 0.0010 \\
\hline
\end{tabular}

IQ: Intelligence Quotient; EI: Emotional Intelligence; \#Significantly higher than goalkeepers; "Significantly higher than defenders; *p $<0.05 ;{ }^{\#, * *}$ p $<0.01$.

Table 5. Comparing the Psychological Characteristics of Soccer Players in Different Playing Positions

\begin{tabular}{|c|c|c|c|c|c|c|}
\hline BAR-ON Subscales & $\begin{array}{l}\text { Goalkeepers (n } \\
=30) \text { Mean } \pm \\
\text { SD }\end{array}$ & $\begin{array}{l}\text { Defenders ( } n= \\
\text { 30) Mean } \pm \text { SD }\end{array}$ & $\begin{array}{l}\text { Midfielders (n } \\
=30 \text { ) Mean } \pm \\
\text { SD }\end{array}$ & $\begin{array}{l}\text { Forwards }(n= \\
\text { 30) Mean } \pm \text { SD }\end{array}$ & $\begin{array}{l}\text { F (3, } \\
116)\end{array}$ & $\mathbf{p}$ \\
\hline Problem-solving & $25.45 \pm 0.52^{*}$ & $19.2 \pm 1.32$ & $23.9 \pm 2.7^{* * *}$ & $28.66 \pm 1.24^{2 \alpha^{* * *}}$ & 10.60 & 0.0003 \\
\hline Happiness & $23.66 \pm 2.35$ & $27.5 \pm 2.5$ & $24.9 \pm 2.92$ & $27.25 \pm 1.47$ & 1.756 & 0.1880 \\
\hline Independence & $20 \pm 2.44$ & $20.6 \pm 2.33$ & $22.46 \pm 1.90$ & $20.4 \pm 1.85$ & 1.921 & 0.1557 \\
\hline Stress tolerance & $19 \pm 2.16$ & $15 \pm 1.41$ & $21.18 \pm 1.58^{* *}$ & $24.5 \pm 2.5^{\# * * *}$ & 12.98 & 0.0001 \\
\hline Self-actualization & $26 \pm 2.16$ & $25 \pm 3.34$ & $23.63 \pm 2.45$ & $27 \pm 2.52$ & 1.296 & 0.2997 \\
\hline $\begin{array}{l}\text { Emotional self- } \\
\text { awareness }\end{array}$ & $17.5 \pm 1.5$ & $21.6 \pm 1.35^{\#}$ & $22.27 \pm 1.76^{\# \#}$ & $24.25 \pm 0.82^{\# \#}$ & 7.385 & 0.0020 \\
\hline Reality testing & $18 \pm 3.55$ & $20.72 \pm 3.74$ & $20.72 \pm 3.74$ & $21.6 \pm 2.49$ & 0.8230 & 0.4946 \\
\hline $\begin{array}{l}\text { Interpersonal } \\
\text { relationship }\end{array}$ & $20.66 \pm 3.39$ & $23.2 \pm 1.83$ & $22.92 \pm 1.98$ & $21.8 \pm 3.70$ & 0.7678 & 0.5238 \\
\hline Optimism & $25.33 \pm 0.47$ & $23.4 \pm 3.26$ & $23.85 \pm 3.39$ & $26.6 \pm 1.85$ & 1.182 & 0.3384 \\
\hline Self-regard & $21 \pm 1.15$ & $21 \pm 1.22$ & $25.3 \pm 2.32^{*}$ & $27 \pm 1.87^{\# * *}$ & 7.320 & 0.0026 \\
\hline Impulse control & $20.35 \pm 0.63$ & $16 \pm 2.74$ & $18.75 \pm 2.26$ & $24.6 \pm 1.85^{*}$ & 3.252 & 0.0422 \\
\hline Flexibility & $19.66 \pm 1.94$ & $20.8 \pm 4.11$ & $21.42 \pm 2.63$ & $22.4 \pm 2.57$ & 0.5461 & 0.6557 \\
\hline Social responsibility & $23 \pm 3.74$ & $25.6 \pm 4.22$ & $24.28 \pm 3.43$ & $27.8 \pm 1.6$ & 1.492 & 0.2431 \\
\hline Empathy & $20.66 \pm 4.10$ & $23 \pm 1.26$ & $22 \pm 3.68$ & $22 \pm 4.24$ & 0.2331 & 0.8724 \\
\hline Assertiveness & $17.66 \pm 2.05$ & $17.2 \pm 3.31$ & $19.74 \pm 2.74$ & $20 \pm 2.19$ & 1.258 & 0.3119 \\
\hline
\end{tabular}

"Significantly higher than goalkeepers; "Significantly higher than defenders; ${ }^{\circ}$ Significantly higher than midfielders. ${ }^{\#, *, \alpha p<}$ $0.05 ;{ }^{\#, * * *} \mathrm{p}<0.01 ;{ }^{* * * *} \mathrm{p}<0.001$.

\section{Comparing Psychological Characteristics} of Soccer Players in Different Playing Positions. The psychological characteristics of soccer players in different playing positions were evaluated by comparing the data of Bar-On subscales. It was observed that goalkeepers $(\mathrm{p}<$ $0.05)$, midfielders $(\mathrm{p}<0.01)$, and forwards $(\mathrm{p}<$ 0.001 ) have higher problem-solving ability than defenders and also forwards have higher problemsolving ability than midfielders $(\mathrm{p}<0.05)$.

In addition, midfielders $(\mathrm{p}<0.01)$ and forwards $(\mathrm{p}<0.001)$ are able to tolerate stress more than defenders and forwards more than goalkeepers ( $\mathrm{p}<0.05)$.

Emotional self-awareness was more significant in defenders $(\mathrm{p}<0.05)$, midfielders, and forwards $(\mathrm{p}<0.01)$ in comparison with goalkeepers.

Furthermore, the scores of self-regard were higher in midfielders $(\mathrm{p}<0.05)$ and forwards $(\mathrm{p}<$ $0.01)$ than defenders, and also in forwards than goalkeepers $(\mathrm{p}<0.05)$.

Impulse control was higher in forwards than defenders $(\mathrm{p}<0.05)$.
There was no significant difference between young soccer players in different playing positions in happiness, independence, selfactualization, reality testing, interpersonal relationship, optimism, flexibility, social responsibility, empathy, and assertiveness.

\section{DISCUSSION}

The aim of the current study was to evaluate the probable relation between young soccer players' sports performance and their IQ and EI, as well as comparing the psychological features of the soccer players in different playing positions. The obtained data showed that there was a positive correlation between young soccer players' sports performance and their IQ and EQ. Although, the scores of IQ were not significantly different among the soccer players in different playing positions. But, forwards EI scores were pointedly higher than defenders and goalkeepers, and midfielders' EI scores were markedly higher than defenders. Assessing the 15 subscales of Bar-On emotional intelligence scale displayed that soccer players are significantly different in 5 
of the 15 mental skills subscales including problem-solving, stress tolerance, emotional selfawareness, self-regard, and impulse control. The forward players got higher scores in problemsolving, stress tolerance, self-regard, and impulse control than defenders. Also, the forwards' scores were higher in stress tolerance, emotional selfawareness, and self-regard than goalkeepers. Likewise, forwards scores in problem-solving were higher than midfielders. Furthermore, the midfielders exhibited higher values in problemsolving, stress tolerance, and self-regard when compared to the defenders. The midfielders and defenders' scores were also higher in emotional self-awareness than goalkeepers. In addition, goalkeepers had higher scores in problem-solving than defenders.

In general, almost all physical trainers and coaches try to find information about the factors and variables that might improve their players' performance. This urge increases in higher levels of matches, resulting in seeking new techniques to manage physical, technical, tactical, physiological, nutritional, and psychological factors for the benefit of the team (30).

Among the psychological elements that affect performance and achievement is the level of IQ and EI. Intelligence is a chief factor that can determine victory in sports, especially in sports such as soccer that require to think accurately, rapidly, and react quickly to precede the opposing team. In the present work, a positive correlation was observed between soccer players' IQ and their sports performance. In consistence with our study, Latifah and colleagues observed a positive linear correlation between IQ and performance in Pencak Silat athletes (10). In another recent research on elite female handball players, it was illustrated that there is a correlation between IQ and competitive activity efficiency (31).

Furthermore, emotions are able to affect cognition, perception, motivation, neurophysiology, motor expression, behavior, individuals' decisions and feeling, thus either debilitating or facilitating athletes' sport performance $(32,33)$. In this regard, researchers claimed that athletes must be careful about the feelings of other coaching staff, officials, sport administrators, teammates, fans, opponents, as well as their family. They must work and communicate with each other to grasp their best performance (34). Besides, they have to learn to be aware of their own ideals, emotions, and performance states to manage their energy level and achieve the finest performance $(35,36)$. Also, a former study reported that EI is crucial in both team and individual sports and might be one of the most important factors in an athlete's function within a team setting that determines whether or not a team loses or wins (6). In the current study, the Pearson correlation showed that there is a significant linear correlation between EI and sports performance. It can be supposed that with improving EI, sports performance might significantly increase. Another research was also shown that there is a positive significant relationship between non-verbal intelligence and elite volleyball players' performance (9). Actually, EI empowers athletes to process the events which bear emotional load appropriately, deal with the events wisely, control immediate demands, and apply continence. Therefore, considering its significant role in athletes' adaptability to the environment and appropriate emotional control; EI might help decrease burnout and enhance emotional management in athletes (37). Hence, it is recommended to consider the significance of EI and teach athletes to focus on expression, awareness, control, and management of various experienced emotions experienced during the sports events to ensure the ideal performance of the individual players and the team.

As it was illustrated, each playing position has its own psychological skills and demands. An investigation evaluated players of different playing positions of the same sport and found out correlations with psychological skills and playing positions (38). This will seem to be an important area of research, because demands placed upon athletes differ as a function of playing position. Studying the psychological profile of young soccer players is really essential as it could provide a lot of remarkable ideas about the nature of youth soccer. In addition, it can display which parts of sports training programs need to be improved, especially in mental training, particularly in players who will soon join professional soccer teams (39). In line with our results, a previous study reported that forwards demonstrated the highest scores values in some psychological skills such as motivation, activation, and confidence when compared to the midfielders and defenders (7). Another study on young futsal players also showed that the psychological features are different in relation to the playing position (21). 
Furthermore, the Bar-On questionnaire appears to be an applicable test to determine the important psychological characteristics of soccer players in different playing positions. This questionnaire can also provide beneficial information from an individual or a group point of view to employ appropriate specific psychological training and training programs for individuals or the team level. As indicated by previous studies the information on the psychological features of young athletes could be really advantageous and besides the anthropometric and physical indicators, they allow coaches to optimize and individualize the training methods $(3,16)$.

Even though the outcomes of the current investigation might be beneficial to the technical staff to be familiar with the personality of the soccer players, this research also presents some limitations. First of all, knowing the psychological characteristics of young elite soccer players makes it challenging for teams to permit to study these psychological features. Hence, a larger number of players allow more precise conclusions to be established.

\section{CONCLUSION}

The outcomes of this research reinforce that there is a correlation between soccer players' sports performance and their IQ and EQ scores.
Besides, soccer players in different playing positions have different psychological skills. In addition, evidence recommends that young soccer players in Iranian soccer teams could be differentiated by their psychological skills and their playing positions. The results of the current investigation were established upon young Iranian soccer players' population involving of 120 contributors. Therefore, caution must be taken when generalizing the results to other soccer player populations. Moreover, researchers must not overestimate or underestimate the importance of psychological skills and playing positions, but adopt an accurate perception on the subject of psychological skills. Certain limitations of this study should be kept in mind when following further research. Future investigations should focus on the awareness of psychological skills on self-development in soccer, and also the influence of psychological skills on team performance.

\section{ACKNOWLEDGMENTS}

This research did not receive any specific grant from funding agencies in the public, commercial, or not-for-profit sectors.

\section{CONFLICT OF INTEREST}

The authors declare that they have no conflicts of interest.

\section{REFRENCES}

1. Stølen T, Chamari K, Castagna C, Wisløff U. Physiology of soccer. Sport Med. 2005;35(6):501-536. doi: 0.2165/00007256-200535060-00004 pmid: 15974635

2. Gledhill A, Harwood C, Forsdyke D. Psychosocial factors associated with talent development in football: A systematic review. Psychol Sport Exercise. 2017;31:93-112. doi: 10.1016/j.psychsport.2017.04.002

3. Olmedilla A, Ruiz-Barquín R, Ponseti FJ, Robles-Palazón FJ, García-Mas A. Competitive psychological disposition and perception of performance in young female soccer players. Frontiers Psychol. 2019;10:1168. doi: 10.3389/fpsyg.2019.01168 pmid: 31191392

4. Haugaasen M, Toering T, Jordet G. From childhood to senior professional football: A multi-level approach to elite youth football players' engagement in football-specific activities. Psychol Sport Exercise. 2014;15(4):336-344. doi: 10.1016/j.psychsport.2014.02.007

5. Demontrond P, Fournier J, Vaire-Douret L. Optimal psychological states in french sport settings: Flow in sports. Health Psychol Rec Perspective. 2006:125-129.

6. Birwatkar VP. Emotional intelligence: The invisible phenomenon in sports. Europe J Sport Exercise Sci. 2014;3(3):19-31.

7. Najah A, Rejeb RB. The psychological profile of youth male soccer players in different playing positions. Advanc Physic Educat. 2015;5(03):161. doi: 10.4236/ape.2015.53020

8. Van Jaarsveld P. The heart of a winner: Developing your emotional intelligence: Lux Verbi; 2003.

9. Kamkary K, Akbari P, Shokrzadeh S. Effects of personality profiles and profiles of IQ on Elite Athletes Volleyball's Performance. Europe J Experimental Biol. 2012;2(6):2352-2359.

10. Latifah E, Rusdiana A, Ugelta S, Karmini M, editors. Contribution of intelligence and emotional qoutients with performance Athletes Penca Silat. IOP Conference Series: Materials Science and Engineering; 2017.

11. Gagné F. Transforming gifts into talents: The DMGT as a developmental theory. High Abilit Stud. 2004;15(2):119147. 
12. Anderson R, Hanrahan SJ, Mallett CJ. Investigating the optimal psychological state for peak performance in Australian elite athletes. J Appl Sport Psychol. 2014;26(3):318-333. doi: 10.1080/10413200.2014.885915

13. Arthur RA, Fitzwater J, Roberts R, Hardy J, Arthur CA. Psychological skills and "the Paras": The indirect effects of psychological skills on endurance. J Appl Sport Psychol. 2017;29(4):449-465. doi: 10.1080/10413200.2017.1306728

14. Abdullah MR, Musa RM, Maliki ABHMB, Kosni NA, Suppiah PK. Role of psychological factors on the performance of elite soccer players. J Physi Educat Sport. 2016;16(1):170.

15. Bali A. Psychological factors affecting sports performance. Int J Physic Educat Sport Health. 2015;1(6):92-95.

16. Olmedilla A, García-Mas A, Ortega E. Psychological characteristics for sport performance in young players of football, rugby, and basketball. Acción Psicológica. 2017;14(1):7-16. doi: 10.5944/ap.14.1.19249

17. Weiss M. Peak performance-mental game plans for maximizing your athletic potential-kauss, DR. Human Kinetics PUBL INC 1607 N Market ST, Champaign, IL 61820-2200; 1982.

18. Mayer JD, Caruso DR, Salovey P. Selecting a measure of emotional intelligence: The case for ability scales. 2000. doi: 10.1017/CBO9780511807947.019

19. Verissimo R. Emotional intelligence, social support and affect regulation. Acta Médica Portuguesa. 2005;18(5):345-352.

20. Mohammadyfar MA, Khan MS, Tamini BK. The effect of emotional intelligence and job burnout on mental and physical health. J India Academ Appl Psychol. 2009;35(2):219-226.

21. Álvarez-Kurogi L, Onetti W, Fernández-García JC, Castillo-Rodríguez A. Does the psychological profile influence the position of promising young futsal players? PloS One. 2019;14(11):e0224326. doi: 10.1371/journal.pone.0224326 pmid: 31714921

22. Raven J. The Raven's progressive matrices: change and stability over culture and time. Cognitive Psychol. 2000;41(1):1-48. doi: 10.1006/cogp.1999.0735 pmid: 10945921

23. Raven J. The Raven progressive matrices tests: their theoretical basis and measurement model. Use Abuses Intelligence Stud Advanc Spearman Raven's Quest Non-Arbitrary Metrics. 2008:17-68.

24. Emotional B-O-O. Quotient Inventory Toronto: Multi-Health Systems. Toronto Canada. 1997.

25. Bar-On RE, Parker JD. The handbook of emotional intelligence: theory, development, assessment, and application at home, school, and in the workplace: Jossey-Bass; 2000.

26. Dehshiri GR. Normalization of bar-on emotional intelligence questionnaire to evaluate of different aspects of intelligence in students of Tehran universities. Thesis Presented Degree Master Sci Psychol. 2003.

27. Pasand F, Mohammadi N, Soltani E, Bazgir B. Comparison of emotional intelligence in athletes and non-athletes, based on some demographic variables. Europe J Sci Res. 2013;116(3):302-310.

28. Charbonneau D, Barling J, Kelloway EK. Transformational leadership and sports performance: The mediating role of intrinsic motivation 1. J Appl Soc Psychol. 2001;31(7):1521-1534. doi: 10.1111/j.1559-1816.2001.tb02686.x

29. Dehghani M, Saf AD, Vosoughi A, Tebbenouri G, Zarnagh HG. Effectiveness of the mindfulness-acceptancecommitment-based approach on athletic performance and sports competition anxiety: A randomized clinical trial. Electronic Physic. 2018;10(5):6749. doi: 10.19082/6749 pmid: 29997757

30. González JM. The relative age effect in football. Arch Med Deporte. 2007;24:5-13.

31. Strykalenko Y, Shalar O, Huzar V, Voloshinov S, Yuskiv S, Silvestrova H, et al. The correlation between intelligence and competitive activities of elite female handball players. J Physic Educat Sport. 2020;20(1). doi: 10.1002/9781118270011

32. Hanin YL, Tenenbaum G, Eklund RC. Handbook of sport psychology. Emotions in sport: Current issues and perspectives. Hoboken. NJ. Wiley; 2007.

33. Jekauc D, Brand R. How do emotions and feelings regulate physical activity? Frontier Psychol. 2017;8:1145. doi: $10.1080 / 10413200305390$

34. Zizzi S, Deaner H, Hirschhorn D. The relationship between emotional intelligence and performance among college basketball players. J Appl Sport Psychol. 2003;15(3):262-269.

35. Jekauc D, Kittler C. Achtsamkeit im Leistungssport. Leistungssport. 2015;45(6):19-23.

36. Hanin YL, Stambulova NB. Metaphoric description of performance states: An application of the IZOF model. Sport Psychol. 2002;16(4):396-415. doi: 10.1123/tsp.16.4.396

37. Goleman D. Working with emotional intelligence: Bantam; 1998.

38. Cox RH, Yoo HS. Playing position and psychological skill in American football. J Sport Behav. 1995;18(3):183.

39. MacNamara Á. Psychological characteristics of developing excellence. Performance Psychol. 2011:47-64. doi: 10.1016/B978-0-443-06734-1.00004-3 